\title{
Blended Learning Based Optitex Media Development for Students in Fashion Design Education Study Program State University of Medan
}

\author{
Surani $^{1}$, Abdul Hamid', Dina Ampera ${ }^{3}$ \\ ${ }^{1,2,3}$ Postgraduate Educational Technology, Universitas Negeri Medan, Indonesia \\ surani.desain@gmail.com
}

\begin{abstract}
To expand the use of Computer Aided Design (CAD) technology in the competency pattern contruction course in drawing various sleeve patterns, this study aims to develop belended learning based optitex media. With Research \& Development (R\&D) method, Borg and Gall combined with Dick \& Carey instructional system development model, this study develops optitex media as a viable and effective medium to use as a learning resource for learning tutorials to draw various patterns of sleeves based on Optitex PDS 11. Procedure development of instructional media there are 5 stages as follows: (1) The preliminary study, (2) Design software, (3) Gather materials, (4) Creating and producing instructional media, (5) Conduct field reviews in order to evaluate and revise products. Obtaining the average result of the presentation of the learning material expert gave a response of $88.75 \%$, then the design expert gave a response of $84.17 \%$, that the material was suitable for use because it contained material and delivery criteria that met the standards of delivering messages to students and meanwhile learning media experts gave a response of $86.25 \%$ worthy of use because it has been designed in such a way and meets the standards of learning media. In the small group presentation results with an average value of $86.42 \%$. In the results of group presentations with an average value of $91.09 \%$ and in the results of large group /field trial presentations with an average presentation of $92.76 \%$. The results showed that the optitex media to draw various patterns of sleeves was effectively used based on blended learning.
\end{abstract}

Keywords

optitex media; optitex PDS 11 software; based on blended learning; drawing sleeve patterns; development

\section{Introduction}

Education is currently growing rapidly, various kinds of reforms are made in order to increase the quality and quantity of education. The industrial revolution 4.0 comes with various technological innovations that are developing challenging traditional. The presence of technology seeks to facilitate human work, technology is created in accordance with human circumstances and needs.

To be able to face and follow the industrial revolution 4.0, it is necessary to improve one's quality in competing and contributing globally through academic levels. In the education system in Indonesia, this era has had an impact on curriculum reconstruction, becoming a challenge to revitalize education. The curriculum must also shape students with an emphasis on the fields of Science, Technology, Engineering and Mathematic (STEM), referring to ICT-based learning, internet of things, big data and computers, as 
well as entrepreneurship and internships (Revolution, 2019). Then Newhouse (2016) takes an approach based on the experiences he has passed by conducting interdisciplinary measures to STEM combined with the Australian curriculum, with the support of modern digital technology, the potential for students to be greater and challenges easier to achieve.

Blended learning is an approach to education that combines online educational materials and opportunities for interaction online with traditional place-based classroom methods. It requires the physical presence of both teacher and student, with some elements of student control over time, place, path, or pace. While students still attend "brick-andmortar" schools with a teacher present, face-to-face classroom practices are combined with computer-mediated activities regarding content and delivery. Blended learning is also used in professional development and training settings.

Blended learning is highly context-dependent, therefore a universal conception of it is difficult. Some reports have claimed that a lack of consensus on a hard definition of blended learning has led to difficulties in research on its effectiveness. A well-cited 2013 study broadly defined blended learning as a mixture of online and in-person delivery where the online portion effectively replaces some of the face-to-face contact time rather than supplementing it.

Additionally, a 2015 meta-analysis that historically looked back at a comprehensive review of evidence-based research studies around blended learning, found commonalities in defining that blended learning was "considered a combination of traditional $\mathrm{f} 2 \mathrm{f}$ [face to face] modes of instruction with online modes of learning, drawing on technology-mediated instruction, where all participants in the learning process are separated by distance some of the time." This report also found that all of these evidence-based studies concluded that student achievement was higher in blended learning experiences when compared to either fully online or fully face-to-face learning experiences. It is proven that currently technology has provided significant changes to education. Such as the utilization of ICT is believed to be able to expand access to education services and improve the quality of education. Innovative ICT-based learning models continue to develop and are followed by many students or community members. Those who wish to continue learning and apply lifelong learning are provided with various on-line education services and other distance learning models.

The terms "blended learning", "hybrid learning", "technology-mediated instruction", "web-enhanced instruction", and "mixed-mode instruction" are often used interchangeably in research literature.

Although the concepts behind blended learning first developed in the 1960s, the formal terminology to describe it did not take its current form until the late 1990s. One of the earliest uses of the term appears in a 1999 press release, in which the Interactive Learning Centers, an Atlanta-based education business, announced a change of name to EPIC Learning. The release mentions that "The Company currently operates 220 on-line courses, but will begin offering its Internet courseware using the company's Blended Learning methodology."

The term "blended learning" was initially vague, encompassing a wide variety of technologies and pedagogical methods in varying combinations (some making no use of technology whatsoever). In 2006, the term became more concrete with the publication of the first Handbook of Blended Learning by Bonk and Graham. Graham challenged the breadth and ambiguity of the term's definition, and defined "blended learning systems" as learning systems that "combine face-to-face instruction with computer mediated instruction". 
Technology and education cannot be separated, all of which must be in line. Learning activities must use blended learning because e-learning is one way for lecturers and students to use technology (Syakur et al in K. Hamid, 2020). Sipayung (2020) stated that teachers must strive to improve the ability to apply ICT in learning. This can bring an increase in student motivation. Realizing that through the internet can be found various information that can be accessed easily, anytime and anywhere, then the use of the internet becomes a necessity. Not only that, internet users can communicate with other parties in a very easy way through emoderating techniques available on the internet (Indrakasih, 2019).

In a report titled "Defining Blended Learning", researcher Norm Friesen suggests that, in its current form, blended learning "designates the range of possibilities presented by combining Internet and digital media with established classroom forms that require the physical co-presence of teacher and students".

Technology in education is a system or tool that is included in the world of education and can be adopted properly and of course has its benefits, roles and functions. Basically, educational studies will produce educational concepts and practices that can more or less use the media as a learning resource. Responding to competition in terms of the future, especially in the industrial world, university is an educational path that is needed in the academic world and industry requires efforts to innovate, where it is ensured that study programs keep pace with industry needs and remain competitive with other fields of study (Romeo \& Lee, 2013).

State University of Medan is a State Higher Education Institution in North Sumatra, currently managing seven faculties including the Faculty of Engineering which is a faculty that carries out vocational study programs with respective graduation achievement criteria. The fashion design education study program is a teacher training program in the scientific field of fashion or fashion. Its main competence is to be able to organize learning in the field of Dressmaking using innovative learning strategies with the latest technology. In addition to producing prospective educators, the field of fashion design education is also graduates who are industry experts (designers, pattern experts, and sample developers in garment). Therefore, educational institutions in vocational competencies have prepared competent human resources in their fields of expertise. In this case, the role of technology is an influencing one, because it focuses on the side-by-side future of technology and education.

Technology is a means in the form of various kinds of equipment or systems that have functions as needed. CAD (Computer Aided Design) is a technology that is used as a computer-based design tool. CAD is a unit of computer program that is prepared and helps users in the process of designing a product so that the results of a product are of good quality (Sukarno et al., 2014). CAD or computer-aided design and drafting (CADD), is a form of automation that helps designers to improve drawings, specifications, and designrelated elements using special graphic effects and computation of computer programs. Wang \& Ha-Brookshire (2018), explored the competencies needed by the fashion industry to face the era 4.0 with digital competence, developed products using digital-optional and $3 \mathrm{D}$ modules for digital simulations and the result was $97.2 \%$ that the competence needed was competence digital.

A computer program that can be used as a learning medium is Optitex, which is a software for creating computerized clothing patterns that have been programmed on a computer. Optitex itself has several main programs consisting of pattern design systems, markers, grades, modulate, and others. The pattern design system used to design and 
develop this pattern has many advantages. One of them is that the pattern can be designed easily through a modification process from an existing style.

Blended instruction is reportedly more effective than purely face-to-face or purely online classes.[29] Blended learning methods can also result in high levels of student achievement more effective than face-to-face learning.

By using a combination of digital instruction and one-on-one face time, students can work on their own with new concepts which frees teachers up to circulate and support individual students who may need individualized attention. "Rather than playing to the lowest common denominator - as they would in a traditional classroom - teachers can now streamline their instruction to help all students reach their full potential."

Proponents of blended learning argue that incorporating the "asynchronous Internet communication technology" into higher education courses serves to "facilitate a simultaneous independent and collaborative learning experience".

By incorporating information technology into class projects, communication between lecturers and part-time students has improved, and students were able to better evaluate their understanding of course material via the use of "computer-based qualitative and quantitative assessment modules".

Blended learning also has the potential to reduce educational expenses, although some dispute that blended learning is inherently less expensive than traditional classroom learning.

Blended learning can lower costs by putting classrooms in the online space and it essentially replaces pricey textbooks with electronic devices that students often bring themselves to class. E-textbooks, which can be accessed digitally, may also help to drive down textbook budgets. Proponents of blended learning cite the opportunity for data collection and customization of instruction and assessment as two major benefits of this approach.

Blended learning often includes software that automatically collects student data and measures academic progress, providing teachers, students and parents detailed students data. Often, tests are automatically scored, providing instantaneous feedback. Student logins and work times are also measured to ensure accountability. Schools with blended learning programs may also choose to reallocate resources to boost student achievement outcomes.

Students with special talents or interests outside of the available curricula use educational technology to advance their skills or exceed grade restrictions.[38] Blended learning allows for personalized education, replacing the model where a teacher stands in front of the classroom and everyone is expected to stay at the same pace. "Blended learning allows students to work at their own pace, making sure they fully understand new concepts before moving on."

A classroom environment that incorporates blended learning naturally requires learners to demonstrate more autonomy, self-regulation, and independence in order to succeed. If teachers offer a form of initial program orientation before introducing blended learning strategies, it can better prepare students to feel confident navigating the different components and developing a stronger sense of independence.

Some online institutions connect students with instructors via web conference technology to form a digital classroom. These institutions borrow many of the technologies that have popularized online courses at the university level. Some advantages of blended learning, particularly at a Kindergarten to grade 12 level of education, can be found under the general concept of educational technology. It is also one of the most effective ways for personalized learning at scale. 
Blended learning supports the use of standards as a way to manage quality and ease of use. This includes multiple kinds of standards: interoperability standards like the SIF specification from A4L or the Learning Tools Interoperability specification from IMS Global Consortium or academic standards like state standards and Common Core State Standards, which encourage integration of technology into a variety of subjects.

This incorporation is a major contributor to student satisfaction and success in such courses. The use of information and communication technologies have been found to improve student attitudes towards learning.

Dasar (2012) explains that computer patterns provide more efficient time than manual patterns because of the software that simplifies the pattern-making process and shortens the time of the production process. The use of the right pattern-making system affects the results of a garment and the efficiency of the pattern-making process, so that the results of making clothes using computer patterns (Optitex Software) are very efficient in clothing production.

Pattern construction or basic pattern making is the initial competence that you have that determines the results of breaking patterns or pattern pieces whether or not they are good in the future. So by presenting this application to students with practical guidelines for use, it is the initial ability to develop their competence to an advanced level of pattern making. The image provided by optitex is a virtual pattern making, which in reality will show the results of the pattern being made whether or not it is simulated to a human figure.

\section{Research Methods}

This research is generally a research that aims to develop computer-based learning media using Optitex PDS 11 software. This type of research includes development research (Research and Development) in which this research develops a form of learning with collaborative media in a blended learning model.

The development model used in the development of learning media which refers to Research and Development ( $\&$ D) is an adaptation development model of the Borg and Gall development model which has the aim of developing and validating products with learning planning in the development of Dick \& Carey's optitex media. The combination of Borg \& Gall and Dick \& Carey models is divided into 5 stages as follows:

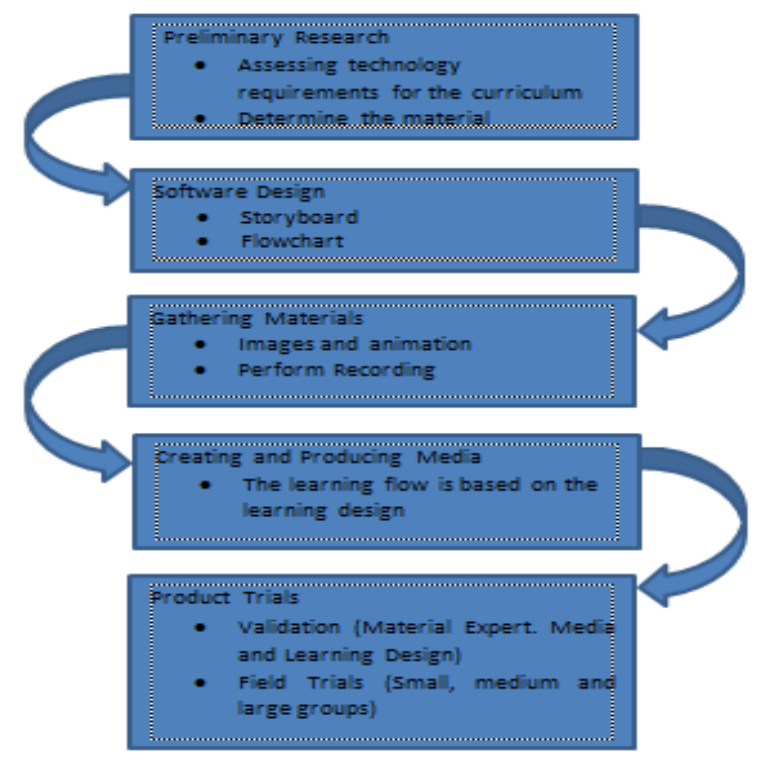

Figure 1. Development Procedure 
To assess products that have been developed, in this development a data collection instrument was used, namely a questionnaire sheet. The questionnaire sheets used as instruments in this study were: (1) questionnaire sheets for material experts, (2) questionnaire sheets for media experts, (3) questionnaire sheets for instructional design experts, (4) questionnaire sheets for students. This research data analysis using quantitative descriptive analysis. All data collected were analyzed using descriptive statistical techniques which are quantitatively separated according to categories to sharpen the judgment in drawing conclusions. Qualitative data in the form of very unfavorable, poor, moderate, good and very good statements were converted into quantitative data with a value scale of 1 to 5 . The results were averaged and used to assess the quality of the learning software. The software criteria will be converted into a value with a scale of five using a Likert scale which is analyzed descriptively in percentage with the following formula (Sugiyono, 2007).

$$
\mathrm{X}=\frac{\text { The total score obtained }}{\text { The sum of the ideal scores of all items }} \times 100 \%
$$

\section{Discussion}

\subsection{Initial Product Description}

Conducting learning analysis and determining learning outcomes is the stage of gathering information about the need for learning media development in the fashion education study program, analyzing the curriculum, pattern construction syllabus, and analyzing the material used in the optitex media to draw various sleeve patterns. The learning outcomes studied in this study were drawing various sleeve patterns. The choice of this material is because in the implementation of learning, most of the breaking of the pattern on the sleeve is a part of drawing and assembling a pattern according to the analysis of the model that is read from a form of an sleeve model that is designed and then made. A pattern that is made must be in accordance with what is planned and exactly according to the desired model. Therefore, it is necessary to develop learning media in the form of video steps to work on the sleeve with the optitex PDS 11 software which is packaged according to learning outcomes and can be used by students to learn independently.

\subsection{The Design of the Optitex Media is Based on Blended Learning}

Designing and developing optitex media for learning using recorded Optitex PDS 11 software to produce steps or sleeve pattern drawing techniques based on a CAD program. In its presentation, the media is applied in Blended Learning learning which is currently taking place as learning that limits face to face. In this study, the blended learning used was SIPDA UNIMED.

\subsection{Test Results}

Analysis of evaluation data ranging from material experts, learning design experts, to learning media experts. If averaged, the percentage of the empirical score from the validation of the three kinds of experts is $86.39 \%$. This percentage is in the "very good" category, in other words. Optitex media draw various patterns of sleeves worthy of being 
tested in the field with revisions based on suggestions and comments of experts. The presentation for each expert validator can be seen in the following figure:

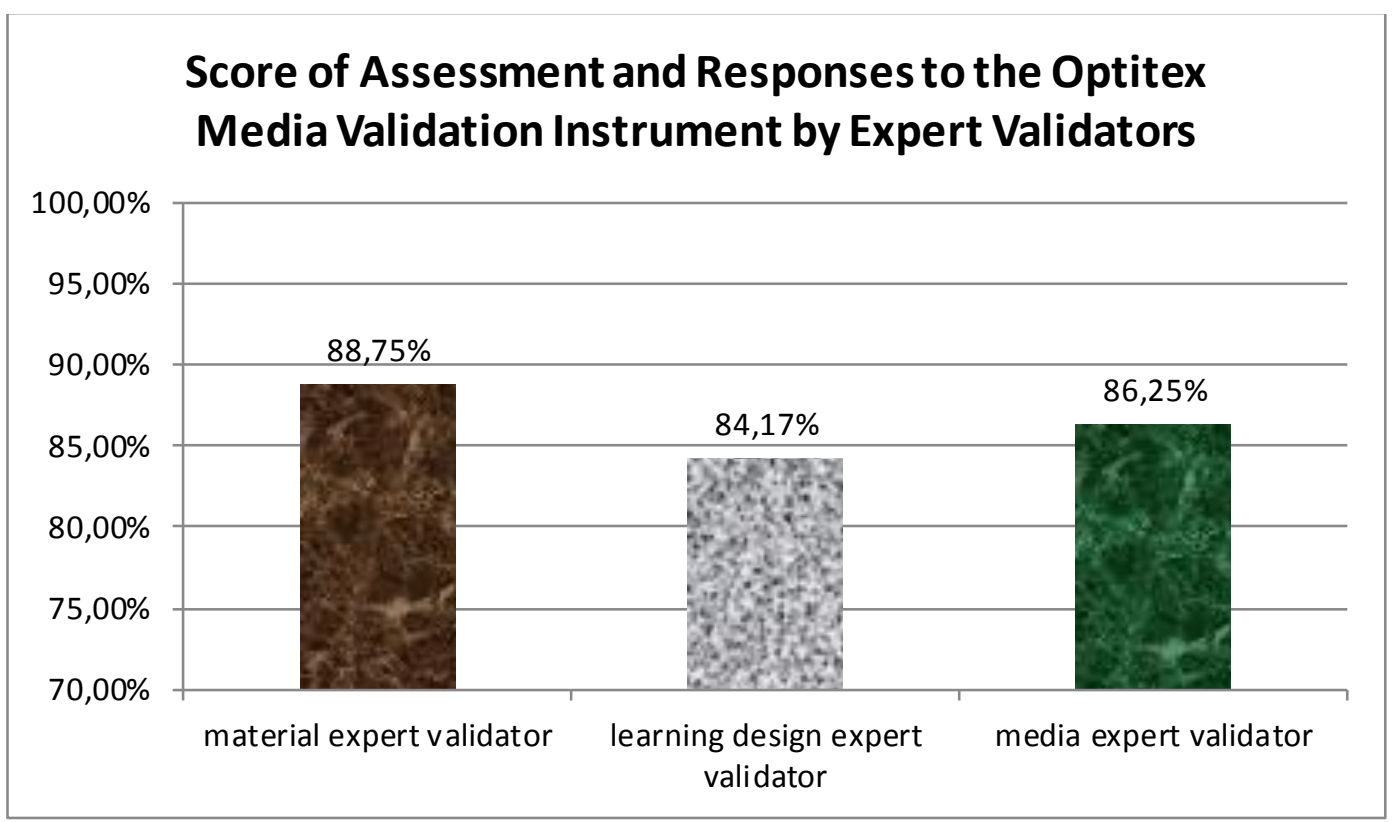

Figure 2. Diagram of the Assessment Score and Response of the Optitex Media Validation Instrument by Expert Validators

Analysis of evaluation data starting from Small Group Trials, Medium Group Trials, and Field Trials (Large Group) if averaged, the percentage of the empirical score from the evaluation of the three types of trials is $90.09 \%$. category "very good". The presentation for media effectiveness can be seen in the following figure:

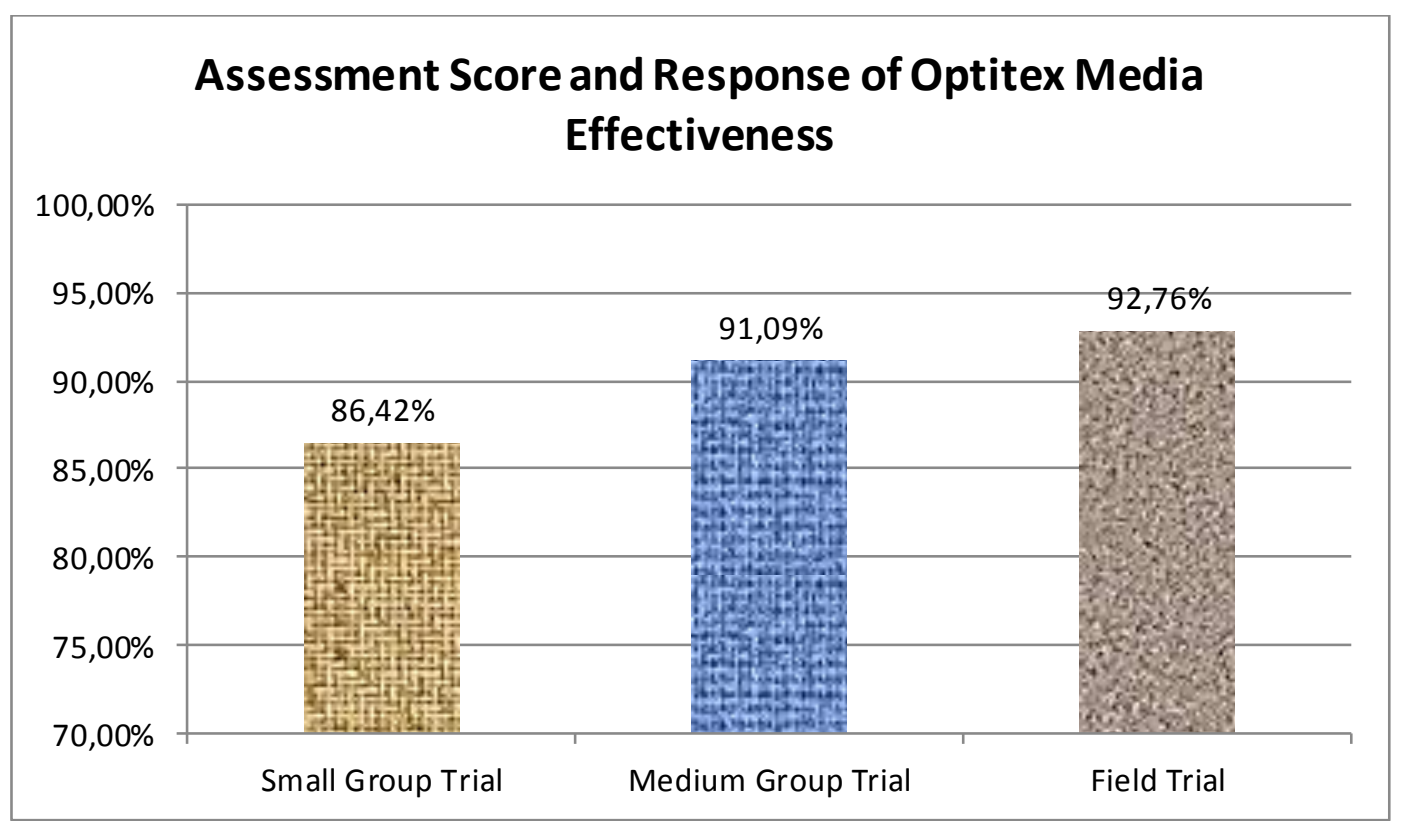

Figure 3. Diagram of the Assessment Score and Response of Optitex Media Effectiveness by Students of Pattern Construction

The product development research conducted is aimed at producing products in the form of optitex media, which is seen as media feasibility and as a new media that supports 
learning. This innovative learning media is expected to be able to complement and improve previous learning which still has several shortcomings, so that obstacles in learning can be minimized. Therefore the role of the media has great potential to stimulate students to respond well to learning. For this reason, learning media provide learning resources that can help the role of educators or lecturers in enriching student insights.

\section{Conclusion}

The media developed was included in the very good category with a percentage of the results of each assessment. With the acquisition of the percentage of the empirical score from the validation of the three kinds of experts is $86.39 \%$, this percentage is in the "very good" category, so it can be accepted and fit for use in the learning process. And the developed blended learning based optitex media is effectively used as a learning medium with the percentage of the empirical score from the evaluation of the three types of trials is $90.09 \%$, this percentage is in the "very good" category, so it is effectively used in the learning process.

\section{References}

Dasar, E. 2012. Universitas Negeri Semarang 2012. 1-77.

Indrakasih, et al. (2019). Development of Basic Volleyball Learning Media Based on Web Learning Materials Towards KKNI at Universitas Negeri Medan. Budapest International Research and Critics in Linguistics and Education (BirLE)Journal Vol 2 (4): 139-144.

Newhouse, C. P. 2016. STEM the Boredom: Engage Students in the Australian Curriculum Using ICT with Problem-Based Learning and Assessment. Journal of Science Education and Technology. https://doi.org/10.1007/s10956-016-9650-4

Revolusi, E. 2019. Pendidikan di Era Revolusi Industri 4.0. November. https://doi.org/10.36588/sundermann.v1i1.18.

Romeo, L. D., \& Lee, Y. A. 2013. Creative and technical design skills: Are college apparel curriculums meeting industry needs? International Journal of Fashion Design, Technology and Education, 6(3), 132-140. https://doi.org/10.1080/17543266.2013.783629.

Sipayung, T.N., et al. (2020). An Analysis of Students Motivation in Online Learning Based on Realistic Mathematical Comic Videos. Budapest International Research and Critics Institute-Journal (BIRCI-Journal) Vol 3 (4): 3861-3871.

Sugiyono. 2007. Metode Penelitian Kuantitatif, Kualitatif, dan R\&d. Bandung: ALFABETA.

Sukarno, R., Sugita, I. W., \& Syaefudin, E. A. 2014. Pelatihan Dasar-Dasar Cad/Cam/Cae Dan Software Autocad Untuk Guru-Guru Smk Bidang Keahlian Teknik Mesin Di $\begin{array}{llll}\text { Wilayah Kabupaten } & \text { Bekasi. }\end{array}$ https://doi.org/10.21009/sarwahita.112.10.

Syakur, A., et al. (2020). The Effectiveness of English Learning Media throughGoogle Classroom inHigher Education. Britain International of Linguistics, Arts and Education (BIoLAE) Journal, 475-483.

Wang, B., \& Ha-Brookshire, J. E. 2018. Exploration of Digital Competency Requirements within the Fashion Supply Chain with an Anticipation of Industry 4.0. International Journal of Fashion Design, Technology and Education, 11(3), 333-342. https://doi.org/10.1080/17543266.2018.1448459. 